\title{
An Analysis of the Ethics of Peer Review and Other Traditional Academic Publishing Practices.
}

\author{
Valentine Cawley
}

\begin{abstract}
Peer review is not what the casual observer thinks it is. In fact, peer review is a deeply troubled process fraught with ethical challenges. This has significant implications for the progress of science. This paper asks the question, of whether peer review is unethical. The matter is analyzed logically and explained with examples. Peer review is found to be intrinsically and structurally unethical, as presently implemented. All the major ethical failings of peer review are identified. Furthermore, other ethical concerns are examined, including the transfer of copyright to publishers, pricing policies and the question of permanence, of a journal. A set of principles is proposed, on how to construct an ethical peer review system, for journals. An ideal, ethical journal is outlined, as an exemplar, that addresses all issues raised. It is hoped that this ethical peer review and journal structure will be implemented, for it promises to speed the advance of science and ensure ready access to human knowledge, for all.
\end{abstract}

Index Terms-Academic publishers, copyright transfer, ethics, peer review.

\section{INTRODUCTION}

Peer review is not the timeless procedure most modern scientists believe it to be. Indeed, it only became virtually universal in science in the 1960s. Before then, decisions on the publishing of papers were often made by journal editors, going by their own experience and understanding. Indeed, Albert Einstein was only ever subject to peer review once. Tellingly, his paper was rejected. Thus, those that defend peer review as the "bedrock of science", are, in fact, on shaky ground. Peer review is very much a late arrival on the scientific scene and, for most of scientific history, Mankind did without it. The question is: were we better off without it? Does peer review come with a set of intractable ethical problems that make it harmful to science?

\section{How Is One To Measure Whether Peer Review Is AN ETHICAL PRACTICE?}

Firstly, one must understand when an action, procedure, situation or set of behaviours is unethical. To understand this I would like to propose two ethical rules:

First identifier of an unethical situation:

A situation is unethical if it intrinsically embodies unethical behavior, in its very nature.

Manuscript received June 20, 2011; revised July 15, 2011.

Valentine Cawley is with Department of Psychology, HELP University, Level 8, Wisma HELP, Jalan Dunggun, Damansara Heights, Kuala Lumpur, 50490. (Email: the.cawleys@gmail.com)
Or

Second identifier of an unethical situation:

A situation is unethical if it allows unethical conduct to occur, then protects unethical people from being punished for their unethical conduct. That is, if the situation shields the wrongdoers from being found out and suffering the consequences, then the situation is unethical, even if, in its nature, it does not breach any ethics.

An example of a situation unethical with regards to the first identifier, would be a young man, who makes his living, by mugging pregnant women, from the back of a motorbike. The situation is intrinsically unethical since there is no way to construe his behavior as ethical conduct. (This is based on a real world example).

An example of a situation unethical with regard to the second identifier would be a householder, who looked out of his window and observed someone burglaring the house across the street. He recognizes the burglar, but says nothing about what he has seen, to the owner of the burgled house. He keeps the burglar's identity secret.

Now it should be noted that there is nothing intrinsically unethical about looking out of the window, as the householder was. However, the onlooker allowed the burglary to take place, without intervening, in any way, thus allowing unethical conduct to take place. Then the onlooker hid the identity of the burglar, thus shielding the burglar from arrest and the consequences of committing a crime. In so doing, the onlooker was being unethical, under the conditions of the second identifier.

To decide if peer review is instrinsically unethical, it should be assessed with these identifiers in mind.

However, firstly we need to ask:

A. Have academics ever encountered ethical failings, with peer review?

In 2008, Science and Engineering Ethics published a paper by David B. Resnik, Christina Guiterrez-Ford, and Shyamal Peddada, entitled "Perceptions of Ethical Problems with Scientific Journal Peer Review: An Exploratory Study". This paper invited scientists to tell of their experiences regarding peer review, in particular the kinds of problems they had encountered. The results are startling, for those who believe that peer review is conducted with integrity.

Here is the table of results from the paper:

Have any of the following ever happened to you, during the peer review process? 
TABLE I: JOURNAL PEER REVIEW SURVEY DATA.

\begin{tabular}{|l|l|l|}
\hline & \% Yes. & SE \\
\hline $\begin{array}{l}\text { A reviewer was } \\
\text { incompetent }\end{array}$ & 61.8 & 3.3 \\
\hline A reviewer was biased & 50.5 & 3.4 \\
\hline $\begin{array}{l}\text { A reviewer required you } \\
\text { to include unnecessary } \\
\text { references to his/her } \\
\text { publication (s) }\end{array}$ & 22.7 & 2.8 \\
\hline $\begin{array}{l}\text { Comments from } \\
\text { reviewers included } \\
\text { personal attacks }\end{array}$ & 17.7 & 2.6 \\
\hline $\begin{array}{l}\text { A reviewer delayed the } \\
\text { review so that he/she } \\
\text { could publish an article } \\
\text { on the same topic }\end{array}$ & 9.6 & 2.0 \\
\hline $\begin{array}{l}\text { A reviewer breeched } \\
\text { confidentiality }\end{array}$ & 6.8 & 1.7 \\
\hline $\begin{array}{l}\text { A reviewer used your } \\
\text { ideas, data or methods } \\
\text { without your permission }\end{array}$ & 4.5 & 1.5 \\
\hline
\end{tabular}

The majority of scientists, in this study, had encountered problems with peer review. Some of those problems are very serious indeed. Some of the practices can only be described as corrupt, in particular, the $9.6 \%$ of scientists whose articles had been deliberately delayed so that the reviewer could publish a similar article elsewhere - and the $4.5 \%$ of scientists whose work had been stolen by the reviewer and used in their own work.

Clearly, peer review is a troubled process given the results of this study. However, do these problems mean that peer review is unethical?

\section{AnAlyzing The Ethics of PeER ReVIEW}

Is peer review unethical when examined with regard to the first identifier of unethical situations?

Firstly, we must state what peer review typically is: it sets up one's anonymous colleagues as judges of one's work. The colleagues are chosen for their familiarity with one's field. Thus, it is that the most likely peer reviewers to be chosen, will be one's closest competitors. This already has the makings of an unethical situation. Peer review gives the power of deciding whether one's work is published, to the very people who would most benefit were it not to be so. Thus, peer review, in its very nature, poses an ethical dilemma to all involved in it: it empowers the reviewer to further his or her own career, by impeding the careers of competitors. This is an intrinsically unethical empowerment.

Furthermore, peer reviewers, in the traditional mode of peer review, are anonymous. Thus, they are both empowered by the decisions they are invited to make, over a competitor's work - and also they are shielded from identification, by the peer review system. Thus, it is that the situation is even more ethically difficult: the structure of peer review empowers reviewers to attack their competitors, whilst simultaneously shielding them from ever being identified and protecting them, in turn, from a counter-attack.

Peer review is doing something very dangerous. It is assuming that one's competitors will behave in an ethically sound manner. It is giving those competitors great power to influence one's career - but, at the same time, protects them from consequence. If peer review is to be fairly conducted then all who are asked to review, must behave ethically. Peer review assumes that they will behave in such a way, without doing anything to ensure that they will. Thus, we can see that the very structure of peer review is innately ethically challenging.

Peer review, itself, creates an opportunity for the unethical to thrive. Its structure is designed to enable the unethical to do harm - and does nothing to protect the innocent scientist from predation. Thus, at the very least, it can be said that peer review is poorly designed, with regards to ethics. With regards to the First Identifier, it is clear that the empowerment of one's competitors to frustrate one's career, is an unethical empowerment and thus, peer review is, by its very nature, unethical in design.

Furthermore, anonymous peer review qualifies as unethical under the Second Identifier for it both creates opportunity for unethical conduct to occur - and shields the wrongdoers from any retribution, by making them anonymous to the victims. This is directly parallel and ethically equivalent, to the onlooker above, who observed a burglary but did not tell on the burglar.

Furthermore, it must be understood, that this unethical status of peer review is structural - that is it is embedded in the very nature of the construct, as it is presently carried out.

\section{PeER ReVIEW'S First FAtAl Flaw: ANONYMity}

The idea that peer reviewers should be anonymous was introduced, presumably, to shield peer reviewers, particularly junior ones, from retaliation from those they review, particularly more senior colleagues. It was so as to give the reviewers the freedom to say whatever they please. However, what has been overlooked, in this implementation, is that granting anonymity to reviewers, empowers them to strike at their competitors with impunity. An anonymous reviewer may steal ideas and results; may delay a paper, so as to allow the publication of their own, similar paper; may block a paper just to stymie a competitor's career; may write an inaccurate review just to create confusion about the merits of a paper and indeed, can do any number of harmful things, without any chance, at all, of facing punishment for having done so. Anonymity completes protects the reviewer from any consequences for any unethical act performed in the course of their reviewing, since the victim cannot find out who has acted against them. Furthermore, it protects them from being recognized as incompetent, should their review prove to be simply ignorant of the science. This allows poor quality work to persist, without any corrective feedback.

These considerations lead me to conclude that:

The first principle of an ideal ethical peer review system is:

In an ideal ethical system of peer review, the reviewers must be made known to the reviewed and to the public. They should be identified by name, affiliation, discipline and speciality.

Should the reviewers remain anonymous, then that system will always lack integrity and will exhibit many failings of ethics and competence. Removing anonymity, is the only 
way to act effectively against these practices.

The full background of the reviewer should be published, so as to enable readers to judge their perspective on the work. This allows readers to better understand why the review was written in the way it was.

\section{The Ethical Status of Variants of Peer Review}

\section{A. Double Blind Peer Review.}

In this variant the reviewer is not known to the reviewed, and the reviewed is not known to the reviewer, at least in theory. However, this is problematic, since scientific fields are often small and there are usually enough clues in a paper for an experienced reviewer to be able to identify his competitor. Let us set aside this problem and assume that there is true two way blindness. How is this situation, ethically?

All the problems remain unaltered by this double blindness. The reviewer still knows he is dealing with a competitor and may be moved to do all of the things that have been identified as problems: that is, steal ideas, delay the paper, give an inaccurate review and so on. The only difference is, this time, he may not be exactly sure which competitor he is attacking. Yet, all the motivations for dishonest conduct remain and the power to obtain advantage through the review system are unaltered by the double blindness. Again, the reviewed will never know who struck against them and the reviewer will be shielded by anonymity.

Ethically, therefore, double blind reviewing is no better, in any way (except the one discussed below, the pursuance of personal vendetta) than the traditional single blind review, in which only the reviewer is anonymous but the reviewed is known to the reviewer.

\section{B. Single Blind Peer Review}

This is the standard variant of peer review. The peer reviewer is anonymous, but the identity of the reviewed is known to the reviewer.

This suffers from all possible ethical problems of peer review plus one: the peer reviewer will be certain of the identity of the reviewed and may pursue personal vendetta, founded on old enmity, thereby. Thus, in this version, if the reviewed is unlucky, his or her work will be reviewed by someone with an active dislike for him or her, resulting in a very strongly negative review. Note that $17.7 \%$ of the respondents in the survey of ethical problems with peer review mentioned above [1], had experienced personal attacks in reviews. These are probably the result of just this kind of reviewer-reviewed background relationship.

\section{Partial Open Review (Single Blind)}

I term "partial open review" a review system, in which the reviewer remains anonymous, but in which the review, itself, is published, for public view, probably on the internet. An example of this kind of review system is the online journal Philica, in which reviews are publicly visible, but reviewers remain unknown.

This system has the advantage that the reader of an article is aware of the views of the reviewer and can judge, for themselves, whether the review is a fair one and may weigh its points for themselves. This is an improvement over the present dominant system in which both reviews and reviewers remain secret.

This review system has greater fairness than a traditional review in that it is relatively easy to determine whether a reviewer is being biased (as many reviews are, according to[1]), incompetent, or in any way malign. Thus, this may act as a brake on the impulse to be unethical, that some reviewers experience.

However, it is not perfect, for the identities of the reviewers still remains unknown and thus they are still shielded from being identified as the guilty party, should there be any misdeed. Furthermore, the identity of the reviewed is still known to the reviewer, which may, of course, inspire grudge reviewing.

\section{Open Review (No Blind)}

Completely open review is one in which neither the reviewer nor the reviewed is anonymous and the reviews themselves are published for all to see.

This system has many advantages. The first is that the reviewer will suffer retribution of a professional kind, should they exhibit any unethical behavior. They will be readily identifiable, should they steal ideas, or delay publication, or in any other way, impede their competitors. Thus, this kind of behavior would be strongly discouraged by an open peer review system.

However, it is, again, not ideal, for there may be elements of unconscious or conscious bias which enter a review, because the reviewer knows the identity of the reviewed. Thus, some old school scientists might view a woman's work, as less interesting, scientifically, because they have an engrained bias against women - or they may have a personal grudge against a particular researcher and may, again, show bias in their review.

Yet is an improvement over all other review systems looked at so far, particularly because the reviewers' names will be attached to their published reviews. This will encourage them to take more care with their reviews, since their quality will impinge on their reputations. Furthermore, most reviewers would make greater efforts to be seen to be fair. So, this review system would improve the quality of reviews.

There is one objection. Some might say that less established scientists would be unlikely to write negative reviews of more established colleagues. This may be so. However, as long as the reviewer remains fair and true to science, I doubt that there will be any consequences for writing an honest review, as long as it is both honest and competent.

\section{E. Open Review. Blinded Author.}

Now, I am about to suggest something which might seem very odd, but which has much merit, in it. In this variant of open review, the reviewer is known to the reviewed, but the reviewed is unknown to the reviewer. This is the exact opposite of the traditional review - and it is one that has certain advantages.

Firstly, the reviewer is made responsible for their actions, 
in that they are identifiable and any unethical acts can be punished. Secondly, the reviewer is made responsible for their review, because it will be published, alongside their name, thus, they should take care to be fair, honest and competent. Thirdly, the reviewed is unknown to the reviewer, so the reviewer cannot be certain (unless textual clues give it away) that he is reviewing the work of someone he or she dislikes. This makes it much less likely that the reviewer will pursue any kind of vendetta by writing a biased review.

The reviewer will remain unknown to the reviewed, in this variant, until the work is actually published, by which time it is too late for the reviewer to act against the reviewed, over any personal matter.

Traditionalists may object strongly to this proposed version of peer review for they will see something wrong in the one sidedness of it: that the reviewed should know the reviewer, but not vice versa. Perhaps, in answer to that, they should reflect that for half a century that has been precisely the position that all who submitted articles to peer reviewed journals were in. The one sidedness was the right thing to do - it is just that those who started the system, didn't think it through, and got it the wrong way around.

\section{The SeCond Ethical Flaw of PeER ReVIEW: REJECTING AN ARTICLE}

Is it ethical to reject an academic article for publication? The immediate reaction of most on reading that question would be: "Of course it is!" However, the question must be both asked and properly answered.

Imagine that a philosopher writes an article on ethics, that identifies a new category of ethical wrongdoing that people are unaware that they are doing wrong. Would it be ethical to block the publication of this article, in peer review, for any reason at all?

It would not be ethical to reject this article. The reason should be clear: by rejecting the article and preventing its publication the peer reviewer would be preventing people from learning about the ethical wrongdoing that is the subject of the article. Thus, they would be ensuring that the ethical wrongdoing would continue unabated. This is, in itself, ethically wrong. The reviewer would, therefore, be being unethical to prevent publication of any article which identifies an ethical wrongdoing.

This article is an example of one which identifies ethical wrongdoing. Therefore it is in the category of articles which cannot be blocked from publication, by peer review, without the peer reviewer having acted in an unethical fashion. Yet, I do worry that peer reviewers may not act in an ethical fashion, with regards to this article. If you are reading this article in a peer reviewed journal, then you know that the reviewer acted ethically, in this regard at least.

So, I have established that there is, at least, one category of articles that cannot be rejected without committing an unethical act. Are there other such categories?

Yes. It could be argued that if an article contains knowledge that is not known to the world and which would be of benefit for the world to know, then it would not be ethical to block publication of that article, for to do so, would be to deprive the world of that knowledge or benefit, perhaps indefinitely, or at least, delaying it, to the detriment of the people of the world.

Yet, that is what peer reviewers do every day. They block publication of articles that contain new knowledge and thereby deprive the world of that knowledge. In doing so, they are, in fact, acting unethically, whatever their true intention might be. Their actions are unethical because their decisions cause harm to the people of the world by depriving them of the benefit of the knowledge contained within the rejected articles.

Those who defend peer review may argue that it exists partially to ensure "quality" of the articles. Yet, this is a false assumption. There are many instances, in science, of fraudulent articles passing peer review, [2] or ones which had many scientific errors in them. So, peer review is not very good at ensuring "quality". What peer review is very good at is in delaying the publication of good science. I have personal experience of this. One of my articles has been under review, now, at a journal for twenty months. The editor says he really likes it and wants to publish it, but he is having arguments with other reviewers and editors who don't like it, so much. To me, they seem to be seeking to delay an article that has revolutionary content, so that they might, perhaps, be able to publish their own. The idea contained within the article, is startlingly new...yet it is stalled in peer review.

This is another problem for peer review. New ideas, ideas that change the world, are likely to meet resistance from the old guard reviewers who believe the world to be otherwise. Thus, new ideas may, in fact, be the hardest to publish, in a peer reviewed journal. New work, may meet most resistance. This is just a theoretical suggestion of mine, for I have no data for it - however, it is a logically likely problem. New ideas have always encountered public resistance in past scientific debates. Now, however, in the world of peer review, that resistance, can go about its work in private and completely prevent the publication of new ideas, in the first place.

This practice, of resisting new ideas and stalling or preventing their publication, is most harmful to science and the people of the world, and therefore ethically dubious. This leads me to propose:

The second principle of an ideal ethical peer review system:

Peer review shall not serve to prevent the publication of articles, but only serve to assess their merits, post-publication.

Post publication peer review will serve to allow the highlighting of demonstrably false, or inadequate work and act as sufficient "quality control", to allow readers to properly assess a work, without acting like the censor of pre-publication peer review, which often prevents work from being aired at all.

\section{The Third EthicAl Flaw OF PEer REVIEW: PUBLICATION DELAYS}

Science is an accumulative enterprise: new work advances 
the old, refines it, and sometimes transforms it. Most works of science incorporate the works of others into their argument or exposition. Thus it is, that scientists build on each other's work. However, there is a problem for modern science: peer review is slow. In fact, peer review is so slow that it can sometimes take years, for an article to be published. Is this an ethical problem?

A simple example serves to show that it is. Imagine that a scientific result has a bearing on the treatment of a disease. Imagine that the publication of that result would immediately allow the saving of human lives and the relief of human suffering. Imagine then, that this result is delayed in peer review for a couple of years. In that time, many people die or are inappropriately treated by their doctors, for want of knowledge of that scientific result. It is clear, that the delay of publication has harmful consequences, and is, therefore unethical. By delaying publication, perhaps for reasons of personal ambition - for instance, to steal the idea and publish one's own similar article - the reviewers are directly causing the deaths of many people. However, there does not need to be any unethical motivation, in the delay, for the delay itself to be intrinsically unethical.

So, delaying a scientific result, in peer review can be unethical. What about less obvious instances? Well, all science has applications. Some applications are more beneficial to people than others. However, it is a probable truth, that no science is completely useless. Thus, any scientific result will serve to improve the world in some way. Thus, by delaying the publication of a result, peer reviewers are preventing a public good, of varying degrees. The magnitude of this public good will vary from scientific article to scientific article - but the fact remains that there will always be some kind of public good, attached to scientific work. Thus it can be seen that delaying the implementation of that public good, is harmful to the people of the world. So, it is unethical to delay the publication, for that leads to public loss or harm. This conclusion applies to all scientific work, of whatever kind - and may be argued to apply, perhaps with less force, to non-scientific academic work, too.

This leads to:

The third principle of an ideal ethical peer review system:

Publication of all journal articles, should be immediate. Peer review follows publication, it must not precede it, for that would act so as to delay publication, which would be unethical.

Immediate publication has many virtues. It completely prevents successful plagiarism of the article or its ideas, by establishing priority, for the work, instantly. This has many ethical benefits, including ensuring that the scientific historical record is accurate, and that the true originators of any particular work, are the ones credited - and not the quickest plagiarist, with the best publishing contacts.

It also maximizes the rate of scientific development by giving immediate access to the latest research, without delays which can, sometimes, amount to years. This is a considerable public good.

One problem of immediate publication could be that errors may remain in the paper. Furthermore, peer review may identify flaws that need correction. To accommodate this, journals should allow the editing of the published article, to create new, time stamped versions, in response to feedback. However, each time stamped version must remain available, in its original form.

Immediate publication also prevents another ethical problem of rejecting an article. Unethical reviewers can give bad reviews, to prompt the rejection of articles. These articles then have to be sent to other journals. This, however, creates an opportunity for plagiarism, since it opens a window between the day the reviewer saw the article and the day the author gets around to submitting it elsewhere, which can take quite awhile, in busy lives. In that window, the unscrupulous reviewer can submit a similar article, more quickly, than the author, and secure priority on stolen ideas.

Immediate publication of all articles that are relevant to the journal, ensures that no windows of opportunity open up, for the plagiarism of articles, through their rejection and later resubmission elsewhere.

Should, however, a journal feel unable to follow this ideal of immediate publication then they must guard against plagiarism and other ethical failings. To do so, they must ensure that the path of knowledge of the article is entirely traceable, alongside the published article a history of the communication of the article should be published. This should list to whom the article was sent, and when (exact time and day) so as to establish protection for the authors of their work. Any plagiarism of the ideas contained within, could be readily proven using such a record.

\section{What Does Publication MEAN?}

Too often, publication means the release of an article, in a very expensive, limited circulation journal that, ultimately, is seen by very few people. Those who do see it, either have to pay a significant fee for the journal, or be employees of institutions that do. Yet, the scientists who wrote the article, were not paid a fee, by the journal for doing so: so is it ethical for the journal to charge such high fees, for reading it?

The high fees for access to articles, serves to limit the distribution of knowledge. This acts as an impediment to scientific progress, since it may deny individuals access to knowledge which they could act upon and use to change the world for the better, or indeed lead to other scientific work. Thus, high fees for articles have the equivalent ethical status, as publication delays: they serve to restrict timely access to scientific knowledge and, indeed, may prevent some interested parties from ever having access at all. This leads to loss or harm to the global public, and is, thus, unethical.

This leads to:

The fourth principle of an ideal ethical peer review system:

The peer review system should be embedded in an open access publishing framework, that makes all articles available for free, to read, to anyone.

Furthermore, journals should consider it their duty to maximize the distribution of the articles, to as many people as possible. The more limited the circulation of an article, the more restricted is the access to the knowledge and the greater is the impediment to public good and the further advance of science. Thus, journals have an ethical duty to make the 
articles as accessible as possible, to the widest range of people. A journal that is deliberately expensive, and, therefore with a modest circulation, is not being entirely ethical, with regards to its duty to distribute knowledge.

The fifth principle of an ideal ethical peer review system:

The journal should be available, freely, online, in addition to any offline copy that may exist, so as to make it accessible to as many people as possible. Should other media of distribution be invented, the journal should be available through them, too.

To cover their costs, open access journals typically have publishing fees levied on the author or author's institution. It should be ensured that everyone has the ability to publish articles, thus:

The sixth principle of an ideal ethical peer review system:

No-one should be barred from publishing, through the open access journal, by poverty. Full fee waivers, should be available for those who are unable to pay.

\section{The Fourth Fatal Flaw of PeEr ReVIEW: INCOMPETENCE AND BIAS}

Too often, according to the research above, peer reviewers are incompetent in their reviews, giving views which are simply wrong and not supported by the contents of the paper. So, too, just as often, peer reviewers are biased and assess a work with closed minds, unable or unwilling to accept a new point of view. Both types of review are damaging not only in that they can stall publication of an article, but in that those who accept the reviews, without question, are given a false view of the merits of the work.

Thus:

The seventh principle of an ideal ethical peer review system:

The author of a work, and all others, should have a right to publicly critique the reviews of the peer reviewers. These critiques should be published alongside the reviews.

This would mean that the quality of the review itself, would be subject to examination. Poor reviews and poor reviewers would be publicly known. This would be an incentive for reviews to be more carefully written, and more fairly so.

\section{Should Copyright Be Transferred to The PUBLISHER?}

It is usual, in academic publishing, for the publisher to require the author to transfer copyright in their work, to the publisher. The usual reason given for this requirement is to "maximize distribution of the article": see, for example, Elsevier's website under "Author's Rights".[3] the action is marketed as a positive, for the author and his or her work. Yet is this true? Do academic publishers maximize the distribution of articles?

Typically, most modern academic publishers make the articles available in expensive subscription journals, of limited circulation. The readership of these journals often reaches little beyond the libraries of subscribing institutions.
This makes many articles inaccessible to many potentially interested parties. After all, not all Universities, worldwide, are well funded. Many institutions in developing nations have severely constrained resources and modest library facilities that are unable to carry most journals, even ones that institutions in the developed world would consider essential. It is clear that the standard academic publishing model of distributing articles in expensive subscription journals is not, in itself, maximizing distribution of the articles.

Many journals, nowadays, also have an online version, in addition to their printed version. It is estimated [4] that between one third and just over one half of academic journals have an online presence. Unfortunately, however, for the ideal of maximal distribution, these online versions are, again, only accessible via expensive subscriptions, or exorbitant per article charges which are, often, typically, around thirty US dollars, a time. (See, for example, the Journal of Experimental Social Psychology, in which articles are typically thirty-one dollars fifty cents. [5]) There are many institutions, worldwide, which do not have the budgets to give their academics access to these articles, particularly in developing countries. It must also not be forgotten that, even in the developed world, there are budgetary constraints in higher education. These limitations are exacerbated by the immoderate number of academic journals being published today. In 2003, there were estimated to be just under 50,000 academic journals currently active in publishing [4]. It is doubtful whether any University library subscribes to all the available journals - and it seems certain that the majority do not subscribe to most of them: it would simply be too costly. Thus, it is clear, that traditional journals, built on expensive subscription based models, inherently act so as to limit their own circulations. So, if the journals inherently are not seeking maximal distribution of articles, what are they seeking? There is only one benefit to the journals, of the present system: maximal profits. Traditional academic journals are not designed, in the manner of their marketing and distribution, to maximize circulation and access to articles, but are designed to extract the maximum "rent" from subscribing institutions. Traditional academic publishers are sacrificing potential readership of their journals, and the articles they contain, by setting as high a price as possible for their journals. This serves to constrict the number of institutions able to afford subscriptions - particularly in the developing world - but serves to maximize the financial return and profits on publishing.

Thus, it can be seen that, far from maximizing distribution of the articles, the publishers' purpose is to maximize revenues from those articles. In fact, the true purpose of transfer of copyright, to the publisher is to PREVENT publication and restrict distribution. By this I mean that publishers act so as to ensure that no-one else is allowed to compete with their publication of a particular article: they wish to ensure that the only way of reading a particular article is by paying for a subscription to a journal, or a one off article access charge. The academic publishers are placing their own corporate interests before that of science and academia in general, and the authors of the articles, in particular.

What would best serve science and academia? A system in which the academic publisher is allowed to publish an article, 
but the author (s) are also allowed to distribute the article, in any way they are able, would be ideal. Such a system requires that copyright is NOT transferred to the academic publisher. Indeed, there is no need for copyright to ever be transferred, for publication to take place. All that is necessary is for the academic publisher to be given a non-exclusive right to publish the article, in any medium they wish. The academic publisher is still free to set whatever price they wish. However, they should not be able to prevent the author making the article freely available, elsewhere, if they wish, so as to maximize readership. The present system of exorbitant tolls on reading articles, severely constrains the ultimate readership of those articles. Authors should have the freedom to allow access to their articles to anyone who wishes to read them, irrespective of their ability to pay.

Some academic publishers have taken a step towards my suggested position, by allowing authors to publish a "preprint" of their articles in a preprint archive, or even on their own website. They usually require that the author link to the academic publisher's version, and point out that it is the official peer reviewed version and that copyright remains with the publisher. It is to be noted that this compromise position still places a wealth of restrictions on the author, since copyright still has to be transferred to the academic publisher, however, it is an improvement and does go some way to remedying the restricted access to articles inherent in traditional academic publishing.

There are a number of ethical questions associated with the current traditional practices of academic publishers. First among them, is whether traditional practices are inherently unethical in the way they constrain information, at the expense of science and in pursuit of profit. There is a simple way to measure the degree to which a journal is putting its own interests before those of science and the general good. This would be to tally up the total size of the potential audience of any given article, or set of articles, and compare that to the actual size of the readership of those articles reached by the journal.

Thus the degree to which a journal is being unethical with respect to the constraint of readership, $\mathrm{C}$, would be given by:

$\mathrm{C}=1-$ (actual readership/potential fully realized readership) $=1-\mathrm{R} 1 / \mathrm{R} 2$.

In which $\mathrm{R} 1=$ actual readership and $\mathrm{R} 2=$ theoretical maximal, fully realized readership.

Thus it can be seen that if the readership is zero, the constraint of readership, $\mathrm{C}$, is 1 . This means that the journal has successfully prevented anyone from reading the article. This is equivalent to not publishing it at all. If, however, actual readership is equal to the theoretical maximal readership, with all interested parties getting access to the article, then constraint, $\mathrm{C}$, is equal to zero. This is the ideal situation and represents perfect publication. The only type of publications which could reach perfect publication, in modern terms, would be an open access, online journal, free to read - but this would only apply if everyone on Earth, had access to an internet connection, which is clearly not the case, at present. However, such journals do, at least, make a considerable step towards making such complete access possible and provide a model for all journals, who seek to be perfect publications.
It should be noted that the degree to which a journal is unethical with regards to restricting readership is proportional to $\mathrm{C}$, the measurement of constraint of readership.

It is certain that all journals that follow the traditional academic publishing model of high subscription charges and per article levies will have relatively high values for $\mathrm{C}$. There are likely to be quite a few people in the developed world who do not have ready access to the article and certain to be many, perhaps even all, in the developing world who do not have access.

Thus, it can be seen, that in this aspect, at least, all traditional academic publishers are behaving unethically, towards their readership, by constraining their journal readerships, through high tolls for access.

Through restricting access, for maximal profit, academic publishers are profiting at the expense of the progress of science. This can be seen because science can be expected to progress in proportion to the number of participants.

$\mathrm{P} \alpha \mathrm{S}$ where $\mathrm{P}$ is the rate of progress of science and $\mathrm{S}$ is the number of participating scientists.

By restricting readership of articles, through high charges, academic publishers are reducing the number of people who can participate in any debate around a given article, or can be influenced in their thinking by a particular article. Thus, they are reducing the power of articles to influence science and have a productive effect on the world. This is, of course, unethical, for it brings a generalized harm to all, but reducing the rate of accumulation of common good.

Transfer of copyright to the publisher always acts so as to reduce the rights of the author to disseminate an article. In fact, it eliminates those rights entirely. The publisher will then, typically, act so as to maximize their profit from the article. This, unfortunately, does not equate to maximizing their readership for, to do that, the publisher would have to make the articles freely available. No. Publishers do not do that: they, instead, maximize revenue by working out by endeavouring to set the price such that the highest value of readership times cost of article is achieved. This will always be at the cost of reducing readership, since any cost at all, applied to any good, will reduce the number of people who can afford it.

Academic publishers may attempt to justify their costs per article, or journal subscriptions, by stating that the charges need to be so high, to maintain the existence of the journal and, therefore, the opportunity to publish articles at all. This, however, can be seen to be a false justification, since there are very cheap models of publishing now available - such as online journals, in open access style, with no print or traditional publishing costs at all. Such models would involve very low costs of operation and thus would allow for closer to maximum readerships, for minimum cost of infrastructure to reach them.

Another way to gauge the extent to which an academic publisher is infringing against the ideal of maximal readership, is to look at their profits.

It can readily be seen that, since to charge for an article is, inevitably, to reduce the number of people who can afford to read it, that the profits of an organization necessarily reflect a theoretical restriction in readership, even if their attained 
readership is quite large. The very fact that charges have been levied and profits made, will have reduced the total achieved readership in relation to the wealth of their particular markets, globally, in that field. Of course, these considerations do not apply if there is a level of charging which all potential readers in a field can afford, which is other than free.

I wish to propose:

The principal of how to achieve maximal readership

An ideal ethical journal, which maximizes readership, is one that, typically, only recovers its costs in publishing.

Thus, it is evident that an ideal journal with the largest possible readership given its structure and attendant costs, would be one that does not make a profit. Any profits made necessarily come with a reduction in readership, unless, in that particular field, there is a price level which all can afford, and the journal or articles are set at this price. An alternative approach is variable pricing, which shall be discussed below. Note that in some cases, it may be possible for a journal to be subsidized and operating below cost recovery pricing - or even be free. In such cases, readership will be further maximized.

Whilst I am not suggesting that all academic publishing enterprises should be non-profit, this point is worth bearing in mind when evaluating the relative likelihood of a particular publisher's adherence to the highest ethical standards.

\section{The Ethical Value of High Cost Journals}

Traditional academic publishers are inherently discriminatory in their publishing practices. It is clear that developing and Third World countries do not have the funds to pay expensive subscription charges for journals. Thus, traditional academic journals are effectively barring developing nations from access to the articles and information in their journals. This situation exacerbates the developmental differences between developed nations and developing nations, by creating an extreme lopsidedness where access to scientific and other academic information is concerned. It is no exaggeration to say, that, by levying high journal charges, traditional academic publishers are acting so as to support the continuation of poverty in the world's developing nations - for it prevents those countries from having access to the knowledge necessary to leverage their economies upwards and outwards from deprivation, of whatever degree.

There is, however, an ethical solution to this problem. Journals should have a two tier fee structure - with one fee for the developed world and a much lower fee for the developing world. Indeed, this lower fee should, ideally, be free, since many developing nations would struggle to pay any fee at all, for a journal. Academic publishers should consider this two tier fee structure as an investment in future sales, since they are helping the developing nations to develop, thereby. In so doing, they are helping to create future developed nations. Once they are developed, they can become regular customers of the publishers, and pay regular fees.

\section{How Long SHOUld A Journal EXIST?}

Not all articles are "instant stars". Some articles take many years to be discovered and for their relevance and importance to be seen and understood. Thus, it can be seen that it is vital that journal articles, once published, must be available for the long term. Indeed, the only term which does not invoke ethical challenges, is forever.

The principle of eternal publication:

An article must be available forever, once published. There must be no risk that the information within it, will ever be lost.

Ethically, it should be clear that, if an article is ever only temporary in some way, that its publication in this manner is unethical, for it would be to deprive future readers of the chance of reading it, and thus would act so as to limit the public good that comes from the furtherance of science, that is a consequence of the article's contents. Thus, all articles must be immortal, and recorded in a permanent, ever available fashion.

\section{The Question That Must Be Asked: Is There Any NeEd for A PeER ReVIEW System, AT All?}

Peer review is, as we have shown, deeply problematic. It could easily be argued that peer review creates more problems than it solves. One obvious solution to the situation could be to dispose of it altogether - and to publish articles without any peer review at all. Each article would then stand on its own merits and be assessed by its readers. Now, many would object to this, in knee-jerk fashion, but it should be remembered that, for most of human history, all academic publications, such as they were at the time, were free of any formalized peer review. Yet, science advanced - so it is quite possible to dispense with peer review and return to earlier times, when such review had not yet been conceived.

\section{AN Alternative to Formal PeEr ReVIEW: ACADEMIC SOCIAL NETWORKS}

Rather than a formal peer review system, it is quite possible to have an informal one, that takes place over time, subsequent to the publication of an article. This would operate like a social network, in which any academic could comment on the work of any other. I would suggest, however, that none of these commenters be allowed to be anonymous but all should be known to all. This informal, ongoing discussion of articles would serve the purposes attributed to peer review, but do so in such a way that no article need be impeded from publication - for such informal, ongoing review would take place subsequent to publication. This method would benefit from a multitude of viewpoints and could, indeed, be more effective than peer review by two or three reviewers, in highlighting problems and ensuring "quality". 


\section{An Ideal Journal With An IdeAl EthicAl PeER REVIEW SYSTEM}

The purpose of this analysis is to show the way to create a journal that is not only not subject to the ethical flaws of standard peer review, but immune to them. This journal must be "ethics proof"...meaning, constructed so that ethics violations cannot successfully be perpetrated, by anyone involved in deciding on the fate of a journal article. This is the innovation that scientific publishing needs to safeguard the future of science.

A perfect journal will be open access, free to read, available online and offline, and in all ways, technologically possible for a journal to be distributed. The perfect journal will be ubiquitous.

A perfect journal will allow the instant publication of ALL articles, without any delay. Peer review evaluation will take place after publication, but will have no bearing on publication.

A perfect journal will identify all reviewers, so that they may not abuse anonymity, in the service of any unethical conduct.

A perfect journal will publish all reviews, along with the name, affiliation, discipline and speciality of the reviewer.

A perfect journal will allow the author (s) and others, to comment on all peer reviews and highlight their shortcomings.

A perfect journal would allow authors to rewrite their articles, in response to peer reviews, creating time stamped additional versions that could address any issues raised.

A perfect journal will be free to publish in, for those unable to pay. Better funded individuals or institutions will pay a reasonable fee, on a sliding scale, depending on ability to pay.

A perfect journal will only take a non-exclusive license to publish an article, and will not require the transfer of copyright from author to journal.

A perfect journal will be permanent and available to be read, forever. No article within such a journal can ever be lost, in time.

Please note that the perfect journal outlined above, was derived from a logical analysis of the ethical problems of peer review. The ideal journal described eliminates all of the ethical failings of peer review. There are other forms that could be employed that would tackle some of the issues - but a journal would have to be very like this one, to be able to address all of the issues.

Presently, there is no such perfect journal, however, it would be relatively straightforward to establish one. All that is needed is the will to do so.

There are some journals, however, that embody some elements of these principles and ideal qualities. Philica, for instance, has instant publishing and post-publication peer reviewing, [6] though it must be said, that sometimes articles remain unreviewed for very long periods, so this needs to be remedied by active recruiting of peer reviewers.

PLOS One, publishes around $70 \%$ of submitted articles, [7] so it is nearing the ideal of $100 \%$ publication of all articles submitted, though they have some problems over the type of articles they are willing to accept. For instance, $\mathrm{N}=1$ studies are usually not accepted. (From personal experience) So, they are not as open as they could be to types of article.

Presently, science and the general public are ill served by a problematic peer review system. Reform of that system, which follows the structural and ethical guidelines I have laid out here, will lead to an optimal flow of scientific information out into the world, with the minimum of ethical issues. This will optimize the growth rate of scientific knowledge, ensure that new ideas are not repressed and that credit is given to the true originators of ideas. It could, in fact, be the beginning a new scientific renaissance, for at this time, it is my belief that peer review is holding back science. Let us free science and reform peer review.

\section{REFERENCES}

[1] Resnick, D. B., Guiterrez-Ford, C., Peddada S. Perceptions of Ethical Problems with Scientific Journal Peer Review: An Exploratory Study, in Science and Engineering Ethics, 2008.

[2] Abate, T. What's the verdict on peer review?, accessed on October $29^{\text {th }}$, 2010 [Online]. Available: http://www.columbia.edu/cu/21stC/issue-1.1/peer.htm

[3] Author's Rights, n.d. [Online] Available at: http://www.elsevier.com/wps/find/authorsview.authors/copyright accessed 20th June 2011.

[4] Tenopir, C., Online databases - online scholarly journals: how many? [Online]Available http://www.libraryjournal.com/article/CA374956.html accessed $18^{\text {th }}$ June 2011.

[5] Journal of Experimental Social Psychology, [Online] available at www.elsevier.com accessed $19^{\text {th }}$ June 2011.

[6] Philica, n.d, accessed on October 29 $9^{\text {th }}, 2010$. [Online] Available at www.philica.com

[7] PLOS One, n.d, accessed on Wikipedia, October $29^{\text {th }}, 2010$. [Online]. Available at: www. Wikipedia.org.

Valentine Cawley was born near London, in the UK, on Valentine's Day 1968. He gained a B.A, in Natural Sciences, from Cambridge University in 1989 and an M.A. in Natural Sciences, also from Cambridge University, in 1992.

$\mathrm{He}$ is currently a Senior Lecturer in Psychology, at HELP University, in Kuala Lumpur, Malaysia. He has led a diverse life and has, at various times, been a physicist, for the British Government, a writer, of several books, the founder and editor of an arts and entertainment magazine, a performance artist whose work, Lord Valentine the Misplaced, was covered on CNN, Reuters and NBC, an actor, and a teacher. His favourite publication is one that identifies a cause of child prodigiousness: "Synaesthesia promotes child prodigiousness and influences creativity.", by Valentine Cawley and Ainan Celeste Cawley. This will shortly appear in Gifted and Talented International. He also favours: "The synaesthete, a new type of "gifted" student and how to teach them", by Valentine Cawley, in Procedia Social and Behavioral Sciences. He is the co-discoverer, along with his son, of Velociperception, a new sensory perception based on a novel type of synaesthesia. His current research interests focus on giftedness, synaesthesia and ethics and his papers cover a diverse range of subject matter. 